\title{
Evaluation of Pneumonia among Children Under Five Years in A Tertiary Care Hospital, Dhaka, Bangladesh
}

Mohammed Akter Hossan Masud ${ }^{1 *}$ Md. Mashiur Rahman², Md. Shafiul Hoque ${ }^{3}$

\author{
${ }^{1}$ Resident Medical Officer of Pediatrics, FCPS, Dhaka Shishu (Children) Hospital, Dhaka, Bangladesh \\ ${ }^{2}$ Registrar of Pediatrics, DCH, Dhaka Shishu (Children) Hospital, Dhaka, Bangladesh \\ ${ }^{3}$ Associate Professor of Pediatrics, MD, Bangladesh Institute of Child Health, Dhaka Shishu (Children) Hospital, Dhaka, Bangladesh
}

DOI: $10.36347 /$ sjams.2021.v09i04.018

| Received: 09.03.2021 | Accepted: 14.04.2021 | Published: 19.04.2021

*Corresponding author: Mohammed Akter Hossan Masud

\begin{abstract}
Introduction: Pneumonia is an inflammation of the parenchyma of the lungs. It is usually caused by viruses or bacteria. Most serious episodes are caused by bacteria. Pneumonia is classified as very severe, severe and non-severe based on the clinical features with specific treatment for each of them. Children with severe and very severe pneumonia require hospital admission for their treatment. Methods: We did a prospective observational cohort study at Dhaka Shishu (Children) Hospital, Dhaka, Bangladesh over a 6-month period (December 2012 to May 2013) on 150 children below 5 years of age admitted with clinical pneumonia. Data was collected from the legal guardians by interview and by physical examination of the child and from investigation reports. Results: Our study included 150 children admitted with clinical pneumonia, 100(66.7\%) patients were male and 50(33.3\%) were female. Male to female ratio was $2: 1$. The most sensitive and specific signs and symptoms for prediction of pneumonia were cough, tachypnoea and chest wall indrawing. We found that presence of tachypnoea and lower chest wall indrawing can detect most cases of pneumonia. All the children had chest X-rays, which were read by a radiologist. If all clinical signs are negative, chest X-ray findings are unlikely to be positive. Conclusions: Initial observation of the infant may be the most critical component for the diagnosis of pneumonia. Tachypnoea is the most valuable of the individual clinical signs for prediction of radiological pneumonia and can be a sensitive and reasonably specific indicator of respiratory infection. The absence of tachypnoea and chest wall indrawing can safely be used to reduce the number of chest X-rays ordered for children under investigation.

Keywords: Severe Pneumonia, Cyanosis, Hypoxemia, Anaemia, Leukocytosis, Positive CRP.

Copyright $\odot 2021$ The Author(s): This is an open-access article distributed under the terms of the Creative Commons Attribution 4.0 International License (CC BY-NC 4.0) which permits unrestricted use, distribution, and reproduction in any medium for non-commercial use provided the original author and source are credited.
\end{abstract}

\section{INTRODUCTION}

Pneumonia is an inflammation of the parenchyma of the lungs. It is usually caused by viruses or bacteria. Most serious episodes are caused by bacteria [1]. Pneumonia is classified as very severe, severe and non-severe based on the clinical features with specific treatment for each of them [2]. Children with severe and very severe pneumonia require hospital admission for their treatment. Acute lower respiratory tract illness (ALRI) is common among children seen in primary care [1], and accounts for slightly less than $50 \%$ of deaths in children under 1 year and about $20 \%$ of deaths in all hospitalized children under 5 years [2]. The physical differences between the chests of children and adults account for some of the differences in physical signs [3]. According to WHO severe or very severe pneumonia is diagnosed when a child develops cough or difficult breathing plus at least one of the following signs- lower chest wall indrawing, nasal flaring, grunting, central cyanosis, inability to breast feed or drink or vomit everything, convulsion, lethargy or unconsciousness [2]. Pneumonia is a substantial cause of morbidity and mortality in childhood (particularly among children <5yrs of age) throughout the world, with an estimated 146-159 million new episodes per year in developing countries. Pneumonia is estimated to cause approximately 4million deaths among children worldwide [1]. Small children find it difficult to take large breaths, so crackles and wheezes which may be expected only during such a maneuver will not be heard. In ALRI, when the history and physical examination suggest the same diagnosis, chest radiography is rarely necessary; when the 2 are inconsistent, then a radiograph may be helpful [4]. The identification of signs such as rapid breathing and chest retraction is very important in deciding who needs expensive treatment and who does not [5]. Also 
Akter Hossan Masud et al; Sch J App Med Sci, Apr, 2021; 9(4): 578-582

important is the decision to refer a child to hospital, which may be many miles away for many people living in rural areas in developing countries. Our aim was to emphasize the importance of using simple clinical signs such as respiratory rate and chest wall in drawing in detecting ALRI, especially pneumonia, in children.

\section{MeTHODS}

We did a prospective observational cohort study at Dhaka Shishu (Children) Hospital, Dhaka, Bangladesh over a 6-month period (December 2012 to May 2013) for 150 children below 5 years of age admitted with clinical pneumonia (most cases admitted were below this age). Data was collected from the legal guardians by interview and by physical examination of the child and from investigation reports. The number of people staying together and the number of available rooms in the house was recorded. Overcrowding was determined by calculating number of family members per room. The paediatrician admitted all cases on a clinical basis according to World Health Organization criteria: cough with tachypnoea (respiratory rate > $50 / \mathrm{min}$ in infants or $>40 / \mathrm{min}$ in older children), indrawing or wheezing. The respiratory rate was counted for a full minute after lowering the temperature (using cold compresses or paracetamol) to $<38^{\circ} \mathrm{C}$ rectally or $37.5^{\circ} \mathrm{C}$ axillary and before the routine extraction of blood. All children admitted were examined by a specialist in paediatrics and all had chest X-rays which were assessed by a radiologist. No clinical findings were written on the $\mathrm{X}$-ray request.

Exclusion criteria from the study were children with immune deficiency, those known to have asthma, history of foreign body aspiration or chemical pneumonitis, children with failure to thrive and malnutrition, and children with severe upper respiratory tract infection. Malnourished children were excluded because tachypnoea and lower chest wall in drawing are not sufficiently sensitive as predictors of pneumonia in these children [6].

The 150 patients in our study were divided into 2 groups according to the chest X-ray findings: those having lobar pneumonia or bronchopneumonia in 1 or more lobes, and those having normal or hyperinflated chest X-rays. The clinical signs and symptoms of the 2 groups were analyzed and compared with the radiological evidence of pneumonia (gold standard) and their sensitivity and specificity calculated.

\section{RESULTS}

Our study included 150 children admitted with clinical pneumonia, $100(66.7 \%)$ patients were male and $50(33.3 \%)$ were female. Male to female ratio was 2:1. Table 1 shows age distribution of the study patients. It was observed that majority $102(68.0 \%)$ patients belonged to age $\leq 12$ months. The mean age was found $9.49 \pm 6.83$ months with range from 2 months to 36 months. From the chest X-ray findings, 40 children (27\%) had lobar pneumonia in 1 or 2 lobes and 50 children $(34 \%)$ had bronchopneumonia, a total of 90 children $(61 \%)$ with pneumonia diagnosed on a radiological basis. Fifty-seven children (39\%) had normal or hyperinflated chest X-rays. A family history of bronchial asthma or allergy was discovered in 15 children (10\%).

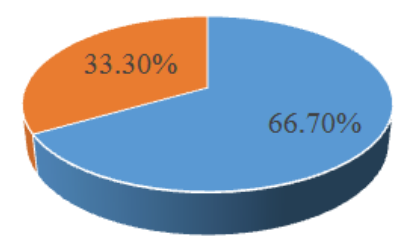

- Male - Female

Fig-1: Pie chart showing distribution of the study patients by sex

Table-1: Distribution of the study patients by age $(\mathbf{n}=150)$

\begin{tabular}{|l|l|l|}
\hline Age (months) & $\begin{array}{l}\text { Number of } \\
\text { patients }\end{array}$ & Percentage \\
\hline$\leq 12$ & 102 & 68.0 \\
\hline $13-24$ & 46 & 30.7 \\
\hline$>24$ & 2 & 1.3 \\
\hline $\begin{array}{l}\text { Mean } \pm \text { SD } \\
\text { Range (min, } \\
\text { max) }\end{array}$ & $\begin{array}{l} \\
(2,36)\end{array}$ \\
\hline
\end{tabular}

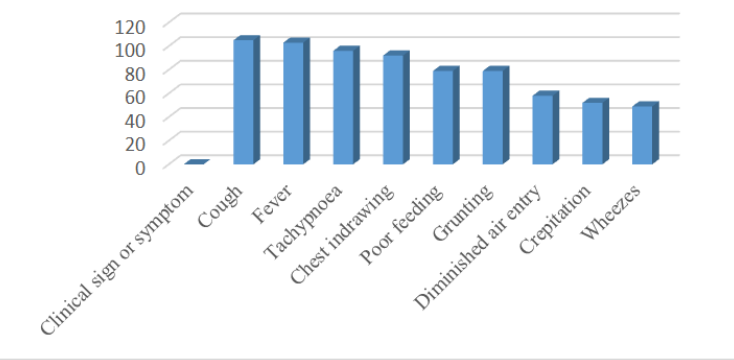

Fig-2: symptoms and signs in children with pneumonia

Table-2: Frequency of symptoms and signs in children with pneumonia $(\mathbf{n}=\mathbf{1 5 0})$

\begin{tabular}{|l|l|l|}
\hline Clinical sign or symptom & No. & \% \\
\hline Cough & 105 & 70.0 \\
\hline Fever & 103 & 68.6 \\
\hline Tachypnoea & 96 & 64.0 \\
\hline Chest indrawing & 92 & 61.3 \\
\hline Poor feeding & 79 & 52.6 \\
\hline Grunting & 79 & 52.6 \\
\hline Diminished air entry & 58 & 38.6 \\
\hline Crepitation & 52 & 34.6 \\
\hline Wheezes & 49 & 32.6 \\
\hline
\end{tabular}


Akter Hossan Masud et al; Sch J App Med Sci, Apr, 2021; 9(4): 578-582

Table-3: Sensitivity and specificity of clinical symptoms and signs at presentation for predicting pneumonia.

\begin{tabular}{|l|l|l|l|l|}
\hline $\begin{array}{l}\text { Clinical sign or } \\
\text { symptom }\end{array}$ & \multicolumn{2}{|l|}{ Chest X-ray } & Sensitivity (\%) & Specificity (\%) \\
\hline & $\begin{array}{l}\text { Pneumonia detected (n } \\
\text { 90) No. positive for } \\
\text { symptom/sign }\end{array}$ & $\begin{array}{l}\text { Normal or hyperinflated } \\
(\mathrm{n}=90) \text { No. positive for } \\
\text { symptom/sign }\end{array}$ & & \\
\hline Tachypnoea & 89 & 7 & 90 & 88 \\
\hline Cough & 88 & 17 & 98 & 70 \\
\hline Chest indrawing & 79 & 13 & 88 & 77 \\
\hline Fever & 70 & 33 & 78 & 42 \\
\hline Poor feeding & 52 & 27 & 58 & 53 \\
\hline Grunting & 52 & 27 & 58 & 53 \\
\hline Diminished air entry & 30 & 28 & 33 & 51 \\
\hline Crepitation & 27 & 25 & 30 & 56 \\
\hline Wheezes & 20 & 29 & 22 & 49 \\
\hline
\end{tabular}

Table-2 shows the overall frequency of symptoms and signs of pneumonia and Table-3 shows their sensitivity and specificity compared with radiology results (gold standard). Cough, fever, tachypnoea and chest indrawing were the most frequently observed signs and symptoms, while tachypnoea was both the most sensitive (99\%) and most specific $(88 \%)$ sign of pneumonia and cough the most sensitive (98\%) symptom. Most of the children (146) received antibiotics.

\section{DISCUSSION}

In developing countries, the case fatality rate from ALRI in children could be reduced if the most serious forms of ALRI were identified and dealt with appropriately. Our study showed that the most sensitive symptom was cough $98 \%$, with $70 \%$ specificity. The most sensitive signs in decreasing order were: tachypnoea $(99 \%)$, chest wall indrawing $(88 \%)$, and fever $(78 \%)$, while the most specific were tachypnoea (88\%) followed by chest wall indrawing (77\%). Anadol found that tachypnoea had a specificity of $99 \%$ and a sensitivity of $61 \%$ and was the most important sign in diagnosing pneumonia [7]. On multivariate analysis, overcrowding, lack of exclusive breast feeding, head nodding on presentation, leukocytosis, positive blood culture and abnormal chest $\mathrm{x}$-ray were associated with need for change of antibiotics and these factors were also associated with prolong hospital stay. Lack of mothers' education, lack of exclusive breast feeding, head nodding, altered sensorium, cyanosis and hypoxemia on presentation, positive CRP and abnormal chest x-ray were determining factors for mechanical ventilation. Mortality was associated with lack of mothers' education, head nodding, altered sensorium, cyanosis, hypoxemia, anaemia, leukocytosis, positive CRP and abnormal chest x-ray. Another study showed that the best screen for pneumonia was the presence of fever along with tachypnoea [8]. A study done in China showed that tachypnoea was more reliable than auscultation in predicting pneumonia [9]. Most of our children were infants, so in our study clinical signs appear to predict pneumonia in infants more reliably than in older children. A study done by Redd et al., comparing the clinical and radiological diagnosis of pneumonia found that children with a radiographic diagnosis tended to have been ill longer and to be older because mothers may have tended to take febrile children with mild ALRI to the health centre or hospital more often than non-febrile children with mild ALRI [10]. In the absence of respiratory signs, febrile infants are unlikely to have abnormal chest radiography [11, 12]. Wheezing was found in $33 \%$ of the children in our study and was not a useful sign for determining pneumonia in children. This is in agreement with a study done by Mahabee-Gittens et al., who found that in wheezy infants and toddlers, grunting along with oxygen saturation is highly specific and can be used to help diagnose pneumonia in wheezing infants and toddlers [13]. We did not differentiate ALRI from bronchial asthma so it is possible that children were over treated for ALRI and undertreated for asthma. In regions where wheezing illness is prevalent, the specificity of the World Health Organization pneumonia algorithm is reduced and this may lead to unnecessary use of antibiotics or underutilization of bronchodilators [14]. Simple physical signs that require minimal expertise to recognize can be used to determine oxygen therapy and to aid in screening for referral [1517]. There may be poor agreement, even among experienced physicians, on the presence of rales in young children, and this was the case in our study. Subcostal or intercostal recessions (difficulty in breathing) are generally more often seen in infants than in older children because the chest wall is more compliant than that of the older child. The most useful single factor for ruling out pneumonia in an infant is the absence of tachypnoea [18]. We found that tachypnoea and chest wall in drawing in the presence of cough can help the clinician to determine the need for chest radiography in the paediatric emergency clinic. A study done in Brazil showed that the clinical symptoms taken together contribute more than the signs and are on a par with X-ray in importance [19]. Another study found that age-specific respiratory rate (recommended by the World Health Organization, with or without chest wall in drawing) is a sensitive and specific indicator of 
Akter Hossan Masud et al; Sch J App Med Sci, Apr, 2021; 9(4): 578-582

pneumonia in almost all age groups [20]. Careful attention to specific clinical factors and use of adjunct radiographs and laboratory tests should guide physicians in selection of antibiotics and decisions regarding hospitalization [21]. The employment of simple clinical criteria gives a good indication of pneumonia and can decrease unnecessary referral and admissions to hospital and thus result in cost-savings. Most of the children in our study received antibiotics, which appear to be used in a high percentage of cases, even if inappropriate for the condition, because these clinical signs do not distinguish viral from bacterial pneumonia, nor do chest X-ray, temperature measurement or duration of fever [22]. Our study justifies the premise that pneumonia case detection does not require auscultation, chest X-ray or laboratory testing, and that observation of the respiratory rate and lower chest wall in drawing are the key elements of assessment in young children. Shah et al., [23], and Coles et al., [24], reported that low birth weight has been associated with development of severe pneumonia. In another study Suwanjutha et al., [25], found Low birth weight has also been reported to be a risk factor for increased mortality. Maternal education emerged as an important determinant in radiographically confirmed pneumonia for prolong hospital stay and need for mechanical ventilation. There are not reports linking maternal education with the outcome of pneumonia [4]. Only possible explanation may be that educated mothers identified illness in their children early and availed early treatment obtained by Tiewsoh et al., [26], However, Gálvez et al., [27], and Anh et al., [28], mentioned that maternal knowledge of symptoms of pneumonia is associated with early recognition and utilization of health care facilities for their children.

\section{CONCLUSiOnS}

Initial observation of the children may be the most critical component for the diagnosis of pneumonia. Tachypnoea is the most valuable of the individual clinical signs for prediction of radiological pneumonia and can be a sensitive and reasonably specific indicator of respiratory infection. The absence of tachypnoea and chest wall indrawing can safely be used to reduce the number of chest X-rays ordered for children under investigation. These findings have relevance for assessment protocols and resulting treatment decisions when chest X-ray is not routinely available. These methods for pneumonia case detection could be taught to primary care physicians, nurses and even mothers, allowing them to seek medical advice early. This would lead to a decrease in the pneumonia mortality rate in children.

\section{REFERENCES}

1. Charles C. Prober, Theodore C. Sectish. Pneumonia. In: Behrman RE, Kliegman RM, Jenson HB, Stanton BF (editors). Nelson Textbook of Paediatrics (18 ${ }^{\text {th }}$ Edition). Philadelphia: WB Saunders Company, 2007. pp. 1795-9.

2. Hospital care for children. World health organization, $2005 . \quad$ Available: http://whqlibdoc.who.int/publications/ 2005/9241546700.pdf. Accessed: 19 November 2012.

3. Helms P, Henderson J, eds. Respiratory disorders. In: Campbell AGM, McIntosh N, eds. Forfar and Arneil's textbook of pediatrics, 5th ed. London, Churchill Livingstone, 1998, 12:489-583.

4. Alario AJ, McCarthy PL, Markowitz R, Kornguth P, Rosenfield N, Leventhal JM. Usefulness of chest radiographs in children with acute lower respiratory tract disease. The Journal of pediatrics. 1987 Aug 1;111(2):187-93.

5. Cherian T, Simoes E, John TJ, Steinhoff M, John M. Evaluation of simple clinical signs for the diagnosis of acute lower respiratory tract infection. The Lancet. 1988 Jul 16;332(8603):125-8.

6. Falade AG, Tschäppeler H, Greenwood BM, Mulholland EK. Use of simple clinical signs to predict pneumonia in young Gambian children: the influence of malnutrition. Bulletin of the World Health Organization. 1995;73(3):299-304.

7. Anadol D, Aydin YZ, Gocmen A. Overdiagnosis of pneumonia in children. Turkish journal of pediatrics, 43(3):205-9.

8. Zukin DD, Hoffman JR, Cleveland RH, Kushner DC, Herman TE. Correlation of pulmonary signs and symptoms with chest radiographs in the pediatric age group. Annals of emergency medicine. 1986 Jul 1;15(7):792-6.

9. Dai Y, Foy HM, Zhu Z, Chen B, Tong F. Respiratory rate and signs in roentgenographically confirmed pneumonia among children in China. The Pediatric infectious disease journal. 1995 Jan $1 ; 14(1): 48-50$.

10. Redd SC, Patrick E, Vreuls R, Metsing M, Moteetee M. Comparison of the clinical and radiographic diagnosis of paediatric pneumonia. Transactions of the Royal Society of Tropical Medicine and Hygiene. 1994 May 1;88(3):307-10.

11. Crain EF, Bulas D, Bijur PE, Goldman HS. Is a chest radiograph necessary in the evaluation of every febrile infant less than 8 weeks of age? Pediatrics. 1991 Oct 1;88(4):821-4.

12. Taylor JA, Del Beccaro M, Done S, Winters W. Establishing clinically relevant standards for tachypnea in febrile children younger than 2 years. Archives of pediatrics \& adolescent medicine. 1995 Mar 1;149(3):283-7.

13. Mahabee-Gittens EM, Dowd MD, Beck JA, Smith SZ. Clinical factors associated with focal infiltrates in wheezing infants and toddlers. Clinical pediatrics. $2000 \mathrm{Jul} ; 39(7): 387-93$.

14. Nascimento-Carvalho C, Rocha H, Santos-Jesus R, Benguigui $Y$. Childhood pneumonia: clinical aspects associated with hospitalization or death. 
Akter Hossan Masud et al; Sch J App Med Sci, Apr, 2021; 9(4): 578-582

Brazilian journal of infectious diseases. 2002 Feb;6(1):22-8.

15. Margolis PA, Ferkol TW, Marsocci S, Super DM, Keyes LL, McNutt R, Harrell Jr FE. Accuracy of the clinical examination in detecting hypoxemia in infants with respiratory illness. The Journal of pediatrics. 1994 Apr 1;124(4):552-60.

16. Usen S, Weber $M$, Mulholland $K$, Jaffar $S$, Oparaugo A, Omosigho C, Adegbola R, Greenwood B. Clinical predictors of hypoxaemia in Gambian children with acute lower respiratory tract infection: prospective cohort study. Bmj. 1999 Jan 9;318(7176):86-91.

17. Weber MW, Usen S, Palmer A, Jaffar S, Mulholland EK. Predictors of hypoxaemia in hospital admissions with acute lower respiratory tract infection in a developing country. Archives of disease in childhood. 1997 Apr 1;76(4):310-4.

18. Bloomfield D. Tachypnea. Pediatrics in review, 2002, 23(8):294-5.

19. Pereira JC, Escuder MM. The importance of clinical symptoms and signs in the diagnosis of community-acquired pneumonia. Journal of tropical pediatrics, 1998, 44(1):18-24.

20. Singhi S, Dhawan A, Kataria S, Walia BN. Validity of clinical signs for the identification of pneumonia in children. Annals of tropical paediatrics. 1994 Jan 1;14(1):53-8.

21. Lichenstein R, Suggs AH, Campbell J. Pediatric pneumonia. Emergency medicine clinics of North America, 2003, 21(2):437-51.

22. Korppi M, Kiekara O, Heiskanen- Kosma T, Soimakallio S. Comparison of radiological findings and microbial aetiology of childhood pneumonia. Acta paediatrica. 1993 Apr;82(4):360-3.

23. Shah N, Ramankutty V, Premila PG, Sathy N. Risk factors for severe pneumonia in children in south Kerala: a hospitalbased case-control study. J Trop Pediatr. 1994; 40: 201-206.

24. Coles CL, Fraser D, Givon-Lavi N, Greenberg D, Gorodischer R, Bar-Ziv J, Dagan R: Nutritional status and diarrheal illness as independent risk factors for alveolar pneumonia. Am J Epidemiol. 2005; 162: 999-1007.

25. Suwanjutha S, Ruangkanchanasetr S, Chantarojanasini T, Ttotrakitya S. Risk factors associated with morbidity and mortality of pneumonia in children under 5 years. Southeast Asian J Trop Med Public Health. 1994; 25(1): 6066.

26. Tiewsoh K, Lodha R, Pandey RM, Broor S, Kalaivani M, Sushil K Kabra. Factors determining the outcome of children hospitalized with severe pneumonia. BMC pediatrics. 2009; 9:15.

27. Gálvez CA, Modeste N, Lee JW, Betancourt H, Wilkins RL. Peruvian mothers' knowledge and recognition of pneumonia in children under 5 years of age. Rev Panam Salud Publica. 2002; 11: 99108.

28. Anh NT, Tram TT, Tri L, Huu TN, Pedersen FK, Mogensen K, Andersen E: Development of ARI case management at primary and secondary level in southern Vietnam. Southeast Asian J Trop Med Public Health. 2000, 31:674-8. 